Y. LU, Y. QIAO, H. XUE, G. ZHOU* (FUDAN UNIVERSITY, SHANGHAI, P. R. OF CHINA) From Colorless to Near-Infrared $S$-Heteroarene Isomers: Unexpected Cycloaromatization of Cyclopenta[b]thiopyran Catalyzed by $\mathrm{PtCl}_{2}$

Org. Lett. 2018, 20, 6632-6635.

\title{
Endo, Exo, and What?
}

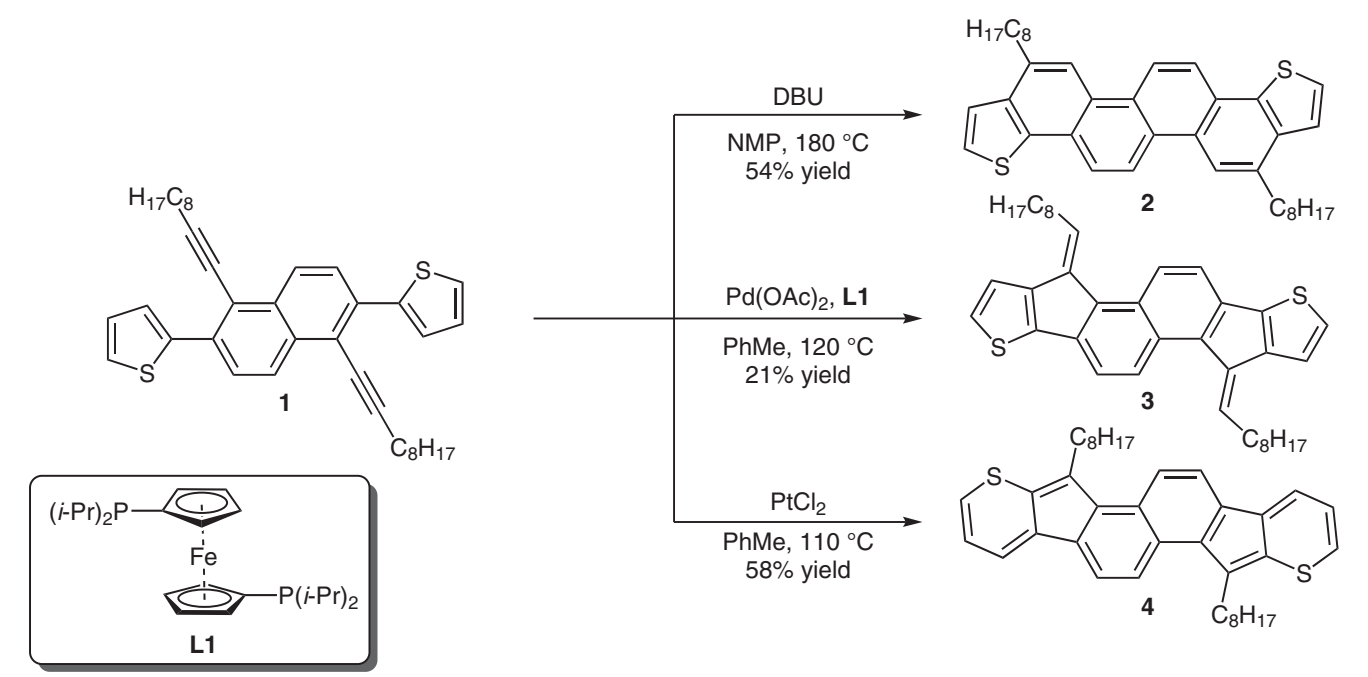

Selected thiopyrans:

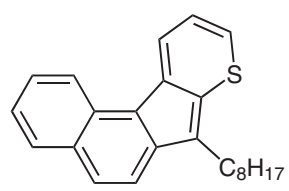

$83 \%$ yield

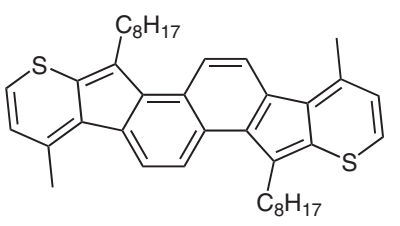

$50 \%$ yield

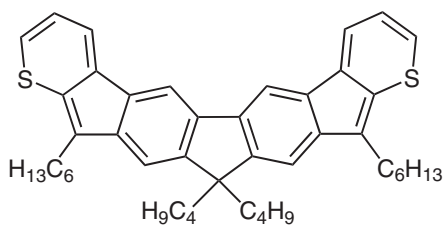

$22 \%$ yield

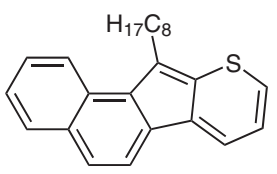

$71 \%$ yield

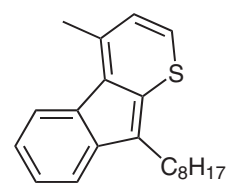

$36 \%$ yield

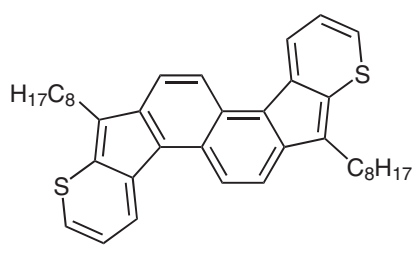

$42 \%$ yield
Significance: The properties of cyclopenta[b]thiopyran and derivatives thereof are largely unexplored, due in part to their challenging synthesis. This methodology, however, provides rapid access to many thiopyran derivatives. Thiopyran $\mathbf{4}$, being isoelectronic to azulene, exhibits many interesting properties, such as strong near-IR absorption and exceptional electrochemical stability, as observed by cyclic voltammetry studies.

\section{Category}

Synthesis of

Materials and

Unnatural Products

\section{Key words}

thiopyrans

polycycles

cycloaromatization

\section{Synfact Month}

Comment: The ability to transform a single compound into a multitude of products with unique properties is particularly useful for the synthesis of functional materials. In this report, the authors cyclize diyne $\mathbf{1}$ to form $\mathbf{2}$ via a 6-endo cyclization, $\mathbf{3}$ via a 5-exo cyclization, and $\mathbf{4}$ via an unexpected skeletal rearrangement. 